\title{
Letter \\ Chaotic nature of sepsis and multiple organ failure cannot be explained by linear statistical methods
}

\author{
Sarah Saliba ${ }^{1}$, Yusuf Alper Kilic ${ }^{2}$ and Selman Uranues ${ }^{1}$
}

${ }^{1}$ Universitätsklinik für Chirurgie, Sektion für Chirurgische Forschung Auenbruggerplatz 29, 8036 Graz, Austria
${ }^{2}$ Hacettepe University Faculty of Medicine Department of General Surgery, 06100, Hacettepe Ankara, Turkey

Corresponding author: Yusuf Alper Kilic, yusufa@hacettepe.edu.tr

Published: 22 April 2008

This article is online at http://ccforum.com/content/12/2/417

(c) 2008 BioMed Central Ltd

Severe sepsis and septic shock represent a major cause of mortality in critical care. Even in patients who survived, a clinical course complicated with multiple organ dysfunction leads to significant morbidity, costs, and use of already limited resources. That's why treatment of these patients requires timely mobilization of a logical and scientifically upto-date plan.

In critical care, as in almost all disciplines of medicine, the emphasis on the benefits of an evidence-based medicine approach has caused current guidelines to be based mostly on the results of prospective randomized clinical studies [1]. These studies mostly evaluate differences in mortality among treatment arms.

But sepsis and multiple organ failure have a chaotic nature, and treatment effects cannot be explained solely on the basis of differences in mortality. That's why we believe that the linear statistical methods currently used in clinical research are not enough to model this chaotic nature.

Besides the complex pathophysiologic interactions within inflammatory cascade and coagulation, a genetically determined predisposition for sepsis and septic shock is another reason that diverts the clinical course of sepsis and septic shock from one that is linearly predictable. Additionally, there is a temporal and dynamic relationship between failing organ systems and therapeutic interventions [2]. It is not unusual to see a patient present to the intensive care unit with a $10 \%$ predicted mortality and die whereas a patient who has an $85 \%$ predicted mortality survives.

On the basis of these observations, we believe that currently used statistical methods using mortality as an endpoint to measure a difference between therapeutic arms are not sufficient to explain the chaotic nature of severe sepsis and septic shock. We believe that statistical methods used in industrial engineering and economics, like time series
Critical Care 2008, 12:417 (doi:10.1186/cc6856)

analysis and forecasting, must be adapted and used for clinical studies among this patient group.

\section{Competing interests}

YAK is the director of Bilgitay Study Group and the Muavenet Intensive Care Information System, which is an open access, online academic information system. The other authors declare that they have no competing interests.

\section{References}

1. Dellinger RP, Levy MM, Carlet JM, Bion J, Parker MM, Jaeschke R, Reinhart K, Angus DC, Brun-Buisson C, Beale R, Calandra T, Dhainaut JF, Gerlach H, Harvey M, Marini JJ, Marshall J, Ranieri M, Ramsay G, Sevransky J, Thompson BT, Townsend S, Vender JS, Zimmerman JL, Vincent JL; International Surviving Sepsis Campaign Guidelines Committee; American Association of CriticalCare Nurses; American College of Chest Physicians; American College of Emergency Physicians; Canadian Critical Care Society; European Society of Clinical Microbiology and Infectious Diseases, et al.: Surviving Sepsis Campaign: international guidelines for management of severe sepsis and septic shock: 2008. Crit Care Med 2008, 36:296-327.

2. Kilic YA, Yorganci K, Sayek I: Visualizing multiple organ failure: a method for analyzing temporal and dynamic relations between failing systems and interventions. Crit Care 2007, 11: 417. 